Auster, $n^{\circ} 22$, e041, 2017. ISSN 2346-8890

Universidad Nacional de La Plata.

Facultad de Humanidades y Ciencias de la Educación

Centro de Estudios Latinos

\title{
Woolf, R., Cicero. The Philosophy of a Roman Sceptic, Londres-Nueva York, Routledge, 2015, 260 + vii pp, ISBN: 978-1-84465-840-4
}

Raphael Woolf se desempeña como docente e investigador del Departamento de Filosofía del King's College de Londres, institución de la que recibió su título de doctor en 1997. Ha enseñado también en Liverpool, Harvard y Princeton. Se dedica a la filosofía antigua, especialmente a Aristóteles, Platón y la filosofía helenística, tal como puede apreciarse en su extenso listado de publicaciones.

En esta oportunidad, ha dirigido su interés hacia Cicerón, con el objetivo de demostrar que no es un mero traductor de ideas filosóficas griegas, como muchas veces ha sido considerado, sino que constituye una voz individual y distintiva, caracterizada por una modalidad propia del escepticismo.

El volumen está organizado en una introducción y cinco capítulos, en los que aborda distintas obras ciceronianas de acuerdo con su tema principal.

En la introducción, titulada "Cicero and philosophy" (pp. 1-9), Woolf explicita su perspectiva de análisis. Es sabido, dice, que muchas veces el papel central que desempeñó Cicerón en la oratoria y en la política romanas de fines de la república ha opacado su contribución a la filosofía. La importancia de la supervivencia de su obra no estriba solamente, para el autor, en el hecho de que nos ha permitido conocer escuelas como el epicureísmo, el escepticismo y la Academia, sino también en que presenta una escritura profunda y sofisticada, escéptica con respecto a Roma, pero también a la filosofía en su conjunto. El hecho de que, a lo largo de su obra, Cicerón justifique en distintas ocasiones por qué se dedica a la filosofía y qué beneficio podía aportarle a la res publica es para Woolf evidencia de que no era vista como una ocupación romana tradicional y una invitación a reflexionar acerca de que toda actividad cultural, por más que aspire a la universalidad, es producto de un tiempo y de un espacio. Woolf se propone, entonces, estudiar la obra de Cicerón en su particularidad y resaltar sus aportes, partiendo de la idea de que "Cicero's philosophical writings are worthy of study for their own sake” (p. 2).

Cita sugerida: Cairo, M. E. (2017). [Revisión del libro Cicero. The Philosophy of a Roman Sceptic de R. Woolf] Auster, (22), e041. Recuperado de: http://doi.org/10.24215/2346889e41 
Luego de la introducción, en cada uno de los cinco capítulos Woolf examina una problemática filosófica distinta, analizando uno o más textos de Cicerón vinculados a ella. El capítulo 2, “Scepticism and certainty” (pp. 10-33), está dedicado al análisis de Academica y se propone estudiar la perspectiva escéptica que luego Cicerón utilizará en obras posteriores. Woolf toma este texto como argumentación a favor de la metodología del escepticismo académico que encontramos en los tratados filosóficos, y aborda cuestiones relativas a la posibilidad de adquirir conocimiento. La metodología del escepticismo se plantea como el motor de una erudición mayor a la que proporciona la adhesión a una sola escuela. En “God, fate and freedom” (34-92) se trata la trilogía de temática religiosa, es decir, De natura deorum, De divinatione y De fato, tratados que indagan la interacción entre la comunidad, el individuo y el concepto de lo divino. Cada una de las tres obras es minuciosamente examinada, y se resalta como logro de Cicerón el debate multifacético logrado mediante su espíritu escéptico, gracias al cual se advierte el problema del vínculo con los dioses a través de la relación entre tradición religiosa y teorización filosófica. El capítulo 4, titulado "The best form of government” (pp. 93-124), estudia las dos obras de filosofía política, De re publica y De legibus. Woolf se detiene en el carácter distintivamente romano que Cicerón confiere a estas cuestiones y debates de modelo claramente platónico, especialmente en el contexto de crisis política de los años 45-44. “The good life in theory and practice” (pp. 125200), quinto capítulo del libro, se ocupa de la discusión ética desplegada en De finibus y De officiis. Los objetivos que deben perseguirse para tener una vida buena, el fin último de la vida, la relación entre naturaleza y cultura, la apropiada justificación para las acciones humanas y las nociones de justicia y sabiduría son las principales cuestiones que Woolf aborda en este capítulo. Finalmente, el capítulo 6, “The role of emotions” (pp. 201-247), está abocada a las Tusculanae disputationes, texto en el que Cicerón discute las emociones no sólo en el nivel teórico sino también en el práctico, con el fin de lograr una vida mejor a través de una adecuada actitud frente al dolor y la muerte, y de la práctica de la virtud.

El volumen se completa con una bibliografía y un índice temático. Se echa realmente en falta una conclusión final, que englobe y sintetice las conclusiones parciales de los distintos capítulos. Más allá de esta pequeña observación, se debe subrayar la importante contribución de Woolf a la bibliografía sobre Cicerón. Su estudio, sin ser estrictamente académico -prescinde, por ejemplo, de notas al pie y de extensas citas en latín-, proporciona un análisis profundo y exhaustivo de las obras del arpinate, deteniéndose en sus nociones 
centrales y subrayando la especificidad de las indagaciones de Cicerón en su contexto histórico, filosófico y político. En síntesis, el libro de Woolf logra su cometido de demostrar la particularidad de los tratados filosóficos ciceronianos y el carácter definitivamente romano de su perspectiva frente al conocimiento, a las emociones, a la relación con los dioses y a la organización de la res publica.

María Emilia Cairo

Universidad Nacional de La Plata - Conicet emiliacairo@conicet.gov.ar 